\title{
Medio siglo de la Sociedad Latinoamericana de Investigación Pediátrica
}

\author{
Fifty years of the Sociedad Latinoamericana de Investigación Pediátrica
}

\author{
"En las reuniones éramos más bien pocos, todos jóvenes, y cada uno traía sus trabajos, \\ y los discutíamos entre todos, con amor y con sana competencia. \\ Había también buena comida. Fueron buenos tiempos..."
}

Carlos Gianantonio ${ }^{1}$

Los niños no son adultos pequeños y necesitan respuestas específicas para sus problemas de salud, que requieren estrategias de investigación propias, frecuentemente obstaculizadas por el "tabú" que ha representado históricamente la investigación en menores. El resultado ha sido, en muchos casos, el retraso en la búsqueda de esas soluciones, y en otros la aplicación de conocimientos originados en la medicina de los adultos para diagnosticar y tratar los problemas de la infancia. Entre otras situaciones, esto derivó en que más de la mitad de los medicamentos que se usan en pediatría no hayan sido aun debidamente evaluados en su seguridad y eficacia en la población infantil.

Algunos caminos se abrieron durante el siglo pasado, especialmente a través de la investigación observacional que brindó importantes respuestas, sobre todo en el campo de la epidemiología. Sin embargo, se debió esperar hasta bien avanzado el siglo para que igual actitud se extendiera a la investigación clínica experimental, particularmente la farmacológica. Recién a finales de la década de 1980 surgieron las primeras iniciativas para favorecer la investigación pediátrica en dicha área, primero en Estados Unidos, luego en Europa y finalmente en algunos de nuestros países. ${ }^{2}$

La Sociedad Latinoamericana de Investigación Pediátrica (SLAIP) y sus miembros participaron de muchos de estos desarrollos con investigaciones originales llevadas a cabo con el más alto estándar ético y metodológico.

Carlos Gianantonio (1926-1995), uno de los socios fundadores, resume, en la nostálgica frase del epígrafe, el espíritu con que fue creada la Sociedad. Había en ese grupo de jóvenes pediatras un ansia de renovación de la práctica profesional casi revolucionaria, no exenta de romanticismo. La pediatría regional de ese momento, heredera de la europea de preguerra, no se aprendía ni se practicaba sin una fuerte carga de empirismo - propio de la "experiencia que dan los años"-que, por otra parte, campeaba en toda la medicina. ${ }^{3}$

Tal vez por ello esos jóvenes, siguiendo los lineamientos de las sociedades homólogas de Estados Unidos (Society for Pediatric Research -SPR-)y Europa (European Society for Pediatric Research-ESPR-), fijaron en su estatuto una edad límite de 45 años para los socios activos, estimando que al alcanzarla deberían haber formado una nueva generación de investigadores jóvenes que los sucedieran con el mismo ímpetu renovador. Con ese espíritu efectuaron su primera reunión en Mendoza, en 1962. ${ }^{3}$

Así vemos que las sociedades de investigación pediátrica, tanto la SLAIP como SPR (fundada en New Haven en 1931) ${ }^{4}$ y ESPR (fundada en Bonn en 1959$)^{5}$ responden a un requerimiento común: desafiar los paradigmas del momento, generar evidencias utilizando la mejor metodología científica y aprovechar la riqueza de la discusión transdiciplinaria. También, con el tiempo, compartieron su principal amenaza: la segmentación del conocimiento y el consecuente alejamiento de sus miembros hacia sociedades que representaran más específicamente sus actividades. De tal forma la SLAIP vio partir a nefrólogos, hematólogos, nutricionistas, endocrinólogos, etc., que se agruparon en sus "propias" sociedades científicas. Si bien cada desgajamiento fue traumático y aún incluso hizo pensar en la viabilidad de la idea original, cada año la SLAIP resurgió con nueva fuerza.

Gianantonio también recuerda que "...esta Sociedad nació en medio de otro proceso histórico de importancia, que fue el de la educación de postgrado en medicina (la residencia)...".Es decir que en el año de la fundación de SLAIP, la práctica profesional, entendida como asistencia-docenciainvestigación, se insinuaba como el nuevo horizonte a alcanzar. La comunidad pediátrica, representada por los jóvenes fundadores, percibió 
que había llegado el momento de establecer este nuevo paradigma del ejercicio profesional, para lo cual la Sociedad debía ser un instrumento de relevante importancia.

Este espíritu se manifiesta en la dinámica de las reuniones anuales, en las que, a diferencia de lo que ocurre en la mayoría de los congresos clásicos, la participación de los asistentes es muy activa, prácticamente todos son autores que exponen sus investigaciones (la razón asistentes/ trabajos es superior a 0,9$).{ }^{6}$ Además, la proporción de estudios de investigación presentados que alcanzan la publicación en forma completa es de $58,6 \%,{ }^{7}$ cifra que supera con holgura las que se acostumbran ver en nuestro medio. ${ }^{8}$

El otro gran desafío que unió a los fundadores de SLAIP fue el intentar abarcar a todos los investigadores pediátricos de la región. Aunque durante años la SLAIP tuvo una clara preponderancia entre sus integrantes de socios provenientes de los principales países involucrados en la fundación (Argentina, Brasil y Chile), este nuevo siglo pone en evidencia un incremento más que significativo de socios de Perú y la incorporación de miembros de Paraguay, México y Bolivia, acercándose así a la idea original.

Esta mirada retrospectiva nos lleva a valorar los logros de los primeros 50 años de la Sociedad. En primer lugar, se destaca el "prodigio" de lozana supervivencia de una entidad prácticamente "virtual" (especialmente al considerar que los primeros 30 años transcurrieron en la era previa a internet). Otro logro considerable es el de desatacar que en una región cuyos países no se han caracterizado por la estabilidad, la regularidad con que se cumplieron las reuniones anuales (48 en 50 años) es algo loable, y, por último y no menos importante, la SLAIP se ha mantenido fiel a su fin: ser un foro de discusión de investigación pediátrica, y colaborar en resolver los problemas de salud de los niños de la región.

Dr. Luis Guimarey

ExSecretario General de SLAIP (2001-2004)

Dr. Fernando Ferrero

ExSecretario General de SLAIP (2010-2013)

http:/ /dx.doi.org/10.5546/aap.2014.300

\section{BIBLIOGRAFÍA}

1. Gianatonio C. Orígenes de la SLAIP, Bs. As. 1994. En una cartilla de SLAIP editada durante la Secretaría General del Dr. Horacio Lejarraga (1993-1995).

2. Gorman RL. The march toward rational therapeutics in children. Pediatr Infect Dis J 2003;22(12):1119-23.

3. Brunser O. Inicios de SLAIP. La creación de la Sociedad Latinoamericana de Investigación Pediátrica [Internet]. Sociedad Latinoamericana de Investigación Pediátrica. [Disponible en: http://www.slaip.org.ar/inicios.htm] [Consulta: 8 de abril de 2014].

4. Zetterström R. European Society of Pediatric Research at its 50th anniversary: past, present, and future. Pediatr Res 2010;68(5):456-8.

5. Weil WB Jr. The Society for Pediatric Research: from infancy to adulthood in sixty-five years. Pediatrics 1996;97(1):129-36.

6. Guimarey L. Perfil de la Sociedad Latinoamericana de Investigación Pediátrica (SLAIP) a 40 años de su fundación. Rev Chil Pediatr 2006;77(1):43-7.

7. Dicembrino M, Anderson M, Vely AG, Ossorio MF, Ferrero F. Full text publications of abstracts presented at Annual Meetings of the Latin American Society for Pediatric Research (SLAIP) [abstract]. En: LI Reunión Annual de SLAIP; 2013, 20-23 de octubre, Viña del Mar, Chile. Pediatr Res 2014;75(3):473.

8. Canosa D,Ferrero F, Melamud A, Otero P, etal.Publicación completa de trabajos presentados en el $33^{\circ}$ Congreso Argentino dePediatría y análisis de factores que impidieron su publicación. Arch Argent Pediatr 2011;109(1):56-65. 